\title{
A phase II clinical trial of gemcitabine and split dose cisplatin in advanced non-small cell lung cancer in an outpatient setting
}

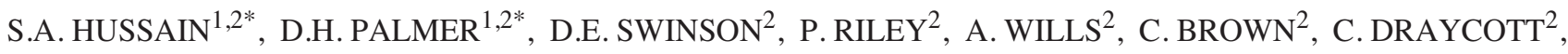 \\ A.EL-MODIR ${ }^{2}$, D.R. PEAKE ${ }^{2}$, D.W. REA ${ }^{1,2}$, A.D.CHETIYAWARDANA ${ }^{2}$ and M.H.CULLEN ${ }^{2}$ \\ ${ }^{1}$ Cancer Research UK Institute for Cancer Studies, University of Birmingham; ${ }^{2}$ University Hospital \\ Birmingham NHS Foundation Trust, Edgbaston, Birmingham B15 2TT, UK
}

Received February 20, 2008; Accepted April 2, 2008

\begin{abstract}
In response to increasing pressure on inpatient services and a meta-analysis indicating that cisplatin (C) is superior to carboplatin, we report a phase II trial of gemcitabine (G) and split-dose $\mathrm{C}$ in advanced non-small cell lung cancer (NSCLC) in an outpatient setting. Patients with stage IIIB/IV NSCLC received: G/C 1250/40 $\mathrm{mg} / \mathrm{m}^{2}$; $\mathrm{G}$ and $\mathrm{C}$ were given on day (d) 1 and d8 in a 21d cycle. Patients with performance status 0-2, adequate bone marrow function and calculated glomerular filtration rate $($ GFR) $>50 \mathrm{ml} / \mathrm{min}$ were eligible. Forty-two patients were enrolled: 25 male; median age 62 (range 37-78) years. There were 26 patients (62\%) with stage IV disease. One hundred and thirty-eight cycles of chemotherapy were delivered. Chemotherapy was well tolerated, allowing maintenance of planned dose intensity (DI) with mean dose delivered of $780.1 \mathrm{mg} / \mathrm{m}^{2}(93 \%)$ and $25.6 \mathrm{mg} / \mathrm{m}^{2}$ (96\%) for $\mathrm{G}$ and $\mathrm{C}$, respectively. The overall response rate was $43 \%$. Median survival was 12.5 months with a median follow-up of 13.5 months. One year survival rate was $51 \%$. G plus $\mathrm{C}$ both given on $\mathrm{d} 1$ and $\mathrm{d} 8$ (q21d) is a very active, well tolerated and convenient outpatient schedule, which maintains DI.
\end{abstract}

\section{Introduction}

Platinum-based chemotherapy is used for most patients with advanced NSCLC and is superior to best supportive care alone in terms of survival and quality of life $(1,2)$. Gemcitabine plus carboplatin $(\mathrm{GCb})$ is the most widely used regimen in the UK (3). Outpatient administration of GCb is considered more convenient than cisplatin-based regimens that require

Correspondence to: Dr Syed A. Hussain, Cancer Research UK Institute for Cancer Studies, University of Birmingham, Edgbaston, Birmingham B15 2TT, UK

E-mail: s.a.hussain@bham.ac.uk

${ }^{*}$ Contributed equally

Key words: gemcitabine, lung cancer, outpatient chemotherapy, phase II clinical trial, split cisplatin admission or protracted outpatient visits for hydration and diuresis. Doubt remains over the relative efficacy of carboplatin $(\mathrm{Cb})$ and cisplatin $(\mathrm{C})$ when given in combination with newer chemotherapeutic agents. Several studies making this comparison show superiority for cisplatin over carboplatin (4-7). Furthermore, a meta-analysis of randomised trials comparing cisplatin to carboplatin has indicated a significant survival advantage favouring cisplatin when combined with a new agent (8).

It has been reported that the optimal dose intensity of cisplatin for NSCLC is between $21-30 \mathrm{mg} / \mathrm{m}^{2} /$ week, equating to either $70-80 \mathrm{mg} / \mathrm{m}^{2}$ q 3-weekly or $100 \mathrm{mg} / \mathrm{m}^{2} \mathrm{q}$ 4-weekly (Raftopoulos H, et al, Proc ASCO 22: abs. 2596, 2003). Administration of a cisplatin dose of this magnitude requires an 8 -h schedule. Such a regimen poses practical difficulties for chemotherapy outpatient departments and the cost of inpatient care can be prohibitive. An out-patient splitdose gemcitabine plus cisplatin regimen involving two 4-h visits may circumvent these issues and facilitate the use of the more active platinum agent without compromising dose intensity.

Experimental data suggest that a combination of gemcitabine and cisplatin given using an appropriate schedule (simultaneous or close proximity exposure) can act synergistically. Synergy may be mediated by inhibition of ribonucleotide reductase by gemcitabine depleting the deoxynucleotide pool required for DNA replication and thereby inhibiting excision repair of cisplatin-induced DNA crosslinks, or by gemcitabine incorporation into DNA facilitating cisplatin crosslink formation $(9,10)$. Thus, splitting the dose of cisplatin over two weeks may increase the potential for synergistic interaction with gemcitabine.

\section{Patients and methods}

Patients with histologically or cytologically confirmed stage IIIB or IV NSCLC were eligible for the study. At least one measurable lesion with a diameter of $\geq 2 \mathrm{~cm}$ was required. Other eligibility criteria were: age $\geq 18$ years; life expectancy $\geq 12$ weeks; WHO performance status $0-2$; adequate haematological function $(\mathrm{Hb} \geq 10.0 \mathrm{~g} / \mathrm{dl}$, neutrophils $\geq 2.0 \times 10^{9} / 1$, platelets $\geq 100 \times 10^{9} / 1$ ) ; adequate renal function (glomerular filtration rate, GFR $\geq 50 \mathrm{ml} / \mathrm{min}$ calculated using Cockcroft formula); adequate liver function (serum bilirubin 
Table I. Dose modification according to hematological toxicity.

\begin{tabular}{lcccc}
\hline & & \multicolumn{2}{c}{ Dose modification } \\
\cline { 3 - 4 } $\begin{array}{l}\text { ANC } \\
10^{9} / 1\end{array}$ & $\begin{array}{c}\text { Platelets } \\
\left(\mathrm{mm}^{3}\right)\end{array}$ & $\begin{array}{c}\text { Gemcitabine } \\
(\%)\end{array}$ & $\begin{array}{c}\text { Cisplatin } \\
(\%)\end{array}$ \\
\hline$>1.0$ & and & $\geq 100,000$ & 100 & 100 \\
$0.5-1.0$ & or & $50,000-99,000$ & 50 & 75 \\
$<0.5$ & or & $<50,000$ & ${\text { Delay } / \text { Omit }^{\mathrm{b}}}^{\mathrm{a}}$ & Delay $^{\mathrm{a} / \text { Omit }^{\mathrm{b}}}$ \\
\hline
\end{tabular}

${ }^{a}$ Day 1 treatments are delayed until haematological status allows treatment. This holds for both 100 and $75 \%$ doses. If the delay is $>3$ weeks, the patient will be withdrawn from the study. ${ }^{b}$ Day 8 treatment is omitted.

within normal limits, AST, ALT, ALP $<1.5$ times upper limit of normal (ULN), or up to 2.5 times ULN in patients with liver metastases and ALP allowed to 2.5 times for bone metastases); women of child bearing potential required a negative pregnancy test prior to entry and both men and women were required to use adequate contraception continued for 3 months after the study. Patients with controlled brain metastases were eligible. Patients were given a trial information leaflet and gave written, informed consent before recruitment into the trial.

Study treatments. Pre-hydration with $1000 \mathrm{ml}$ of $0.9 \%$ saline with $20 \mathrm{mmol}$ potassium chloride and $1 \mathrm{~g}$ magnesium sulphate was given over $2 \mathrm{~h}$. Gemcitabine $\left(1250 \mathrm{mg} / \mathrm{m}^{2}\right)$ was given in $250 \mathrm{ml}$ of $0.9 \%$ saline and infused over $30 \mathrm{~min}$. This was followed by cisplatin $\left(40 \mathrm{mg} / \mathrm{m}^{2}\right)$ given with hydration using $0.9 \%$ saline $(500 \mathrm{ml})$ over $60 \mathrm{~min}$. All drugs were administered via a peripheral intravenous cannula. Antiemetic therapy comprised $8 \mathrm{mg}$ intravenous dexamethasone and $3 \mathrm{mg}$ intravenous granisetron. The total duration of treatment was $\sim 4 \mathrm{~h}$. All patients had haematology and clinical chemistry evaluation within $24 \mathrm{~h}$ before each treatment, and dose modifications based on these are summarised in Table I. Further blood sampling was undertaken on day 15 to monitor toxicity. Patients received a maximum of four cycles of treatment depending on response and toxicity.

Statistical considerations. All patients receiving treatment were included in the toxicity assessment. Survival analysis was performed on an intention-to-treat basis. Data were frozen on 4th of April 2007. Response was evaluated using RECIST criteria, with a central review of imaging by an independent radiologist. Toxicity data were analysed using simple descriptive statistics. Survival curves were calculated according to the method of Kaplan-Meier (11).

\section{Results}

Patient characteristics. A total of 42 patients entered the trial from August 2004 to October 2006. Patient demographics are
Table II. Patient demographics.

\begin{tabular}{lc}
\hline Characteristic & Patient no. \\
\hline Sex & \\
$\quad$ Male & 25 \\
Female & 17 \\
Age & 62 (37-78) \\
$\quad$ Median (range) & \\
Stage & 16 \\
IIIB & 26 \\
IV & \\
Performance status & 5 \\
0 & 32 \\
1 & 5 \\
2 & \\
GFR (ml/min) & 9 \\
50-60 & 33 \\
$>60$ & \\
Post-chemo treatment & \\
Radical surgery & \\
Radical radiotherapy & \\
2nd line chemotherapy & \\
Tyrosine kinase inhibitor & \\
\hline
\end{tabular}

summarised in Table II. Median age was 62 (range 37-78) years, 25 male, 17 female. Sixteen patients had stage IIIB disease and 26 had distant metastases, including 5 with brain metastases treated with cranial radiotherapy prior to chemotherapy. Nine patients had a calculated GFR between 50 and $60 \mathrm{ml} / \mathrm{min}$, which may have excluded them from other cisplatin-based protocols.

Toxicity. One hundred and thirty-eight cycles of chemotherapy were given. Haematological toxicity is summarised in Fig. 1. Twenty-three cycles (15 patients) were complicated by grade 3 neutropenia and 3 cycles ( 3 patients) by grade 4 neutropenia. Eleven of these 26 events occurred on day 8 and required dose modification or delay. The remainder occurred on day 15 and did not influence dose intensity. There were 2 episodes of febrile neutropenia. Both were uncomplicated and were successfully managed with intravenous antibiotics.

There were 6 episodes of grade 3 and 5 episodes of grade 4 thrombocytopenia, none associated with clinical sequelae. All of these occurred on day 15 and recovered by day 1 of the following cycle so that no dose modification or delay was required.

Non-haematological toxicity comprised: 1 episode of gastro-intestinal bleeding; grade 3 nausea and vomiting in 3 patients; grade 3 diarrhoea in 5 patients; grade 3 chest infection in 5 cases; grade 3 rash in 1 patient, which was found to be non-malignant on biopsy and possibly chemotherapy related. Two grade 2 seizures in 1 patient with 
$\mathbf{A}$

Haemoglobin

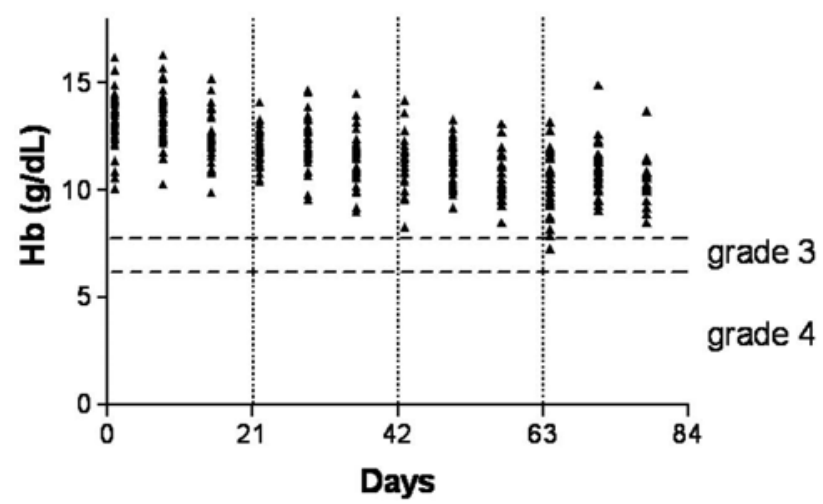

B

Neutrophils

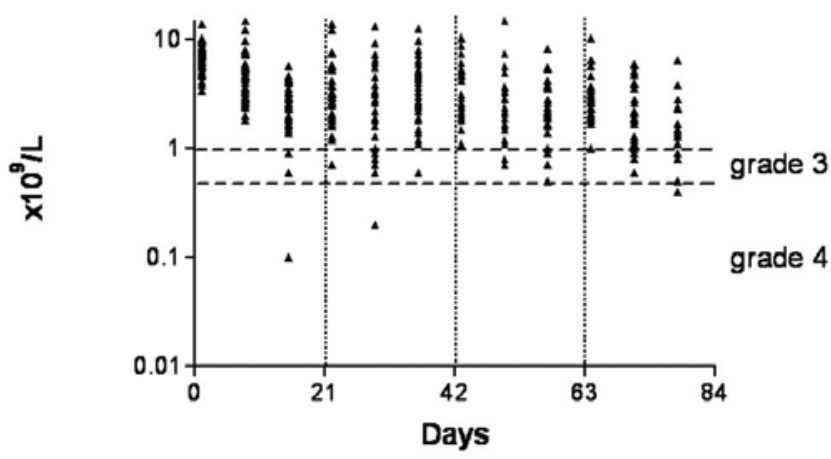

C

Platelets

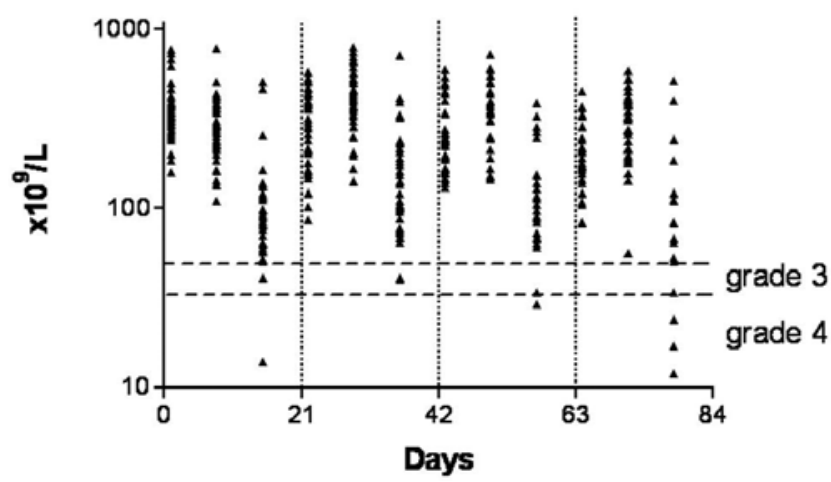

Figure 1. Haematological toxicity. (A) Haemoglobin; (B) Neutrophils; (C) Platelets.

known brain metastases. Grade 2 renal toxicity was seen in 2 patients with a drop in GFR although no clinically significant decline in renal function was noted even in those with baseline GFR between 50-60 ml/min (Fig. 2). No significant neurotoxicity, ototoxicity, or pulmonary toxicity was observed.

Dose intensity. The planned chemotherapy dose per week was $833.3 \mathrm{mg} / \mathrm{m}^{2}$ for gemcitabine and $26.7 \mathrm{mg} / \mathrm{m}^{2}$ for cisplatin. Twenty-six out of 42 patients received the planned dose. A median of $100 \%$ cisplatin dose per cycle (range 88-100\%) and $100 \%$ gemcitabine dose per cycle (range $83-100 \%$ ) were delivered. Mean dose delivered was $780.1 \mathrm{mg} / \mathrm{m}^{2}$ (93\%) for gemcitabine and $25.6 \mathrm{mg} / \mathrm{m}^{2}(96 \%)$ for cisplatin. Cisplatin
GFR

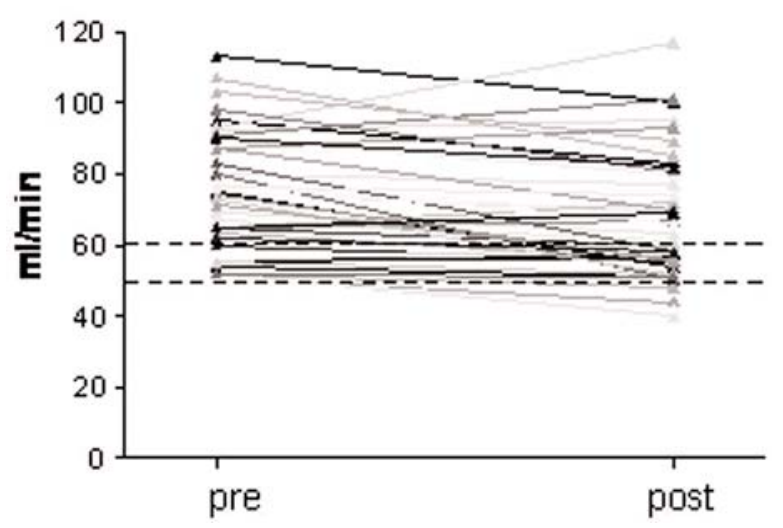

Figure 2. Calculated GFR at baseline and upon completion of chemotherapy.

Table III. Cisplatin dose intensity.

\begin{tabular}{|c|c|c|}
\hline $\begin{array}{l}\text { Cisplatin dose } \\
\left(\mathrm{mg} / \mathrm{m}^{2} / \text { week }\right)\end{array}$ & $\begin{array}{l}\text { Patient no. } \\
\quad(n=42)\end{array}$ & \\
\hline 20 & 1 & \\
\hline 21.5 & 1 & \\
\hline 22.2 & 2 & \\
\hline 22.9 & 1 & \\
\hline 23.3 & $1 \square$ & \\
\hline 23.8 & 3 & $\left(70 \mathrm{mg} / \mathrm{m}^{2}\right.$ in a \\
\hline 25.7 & 7 & 3-weekly cycle) \\
\hline 26.7 (planned dose) & 26 & \\
\hline
\end{tabular}

dose intensity per week is summarized in Table III. Of 138 cycles of chemotherapy (276 doses), only 11 required dose reduction (4\%), 5 dose delays by 1 week $(1.8 \%)$ and 6 dose omissions $(2.2 \%)$.

Response. Efficacy analysis was performed on an intention to treat basis. Eighteen patients achieved a partial response $(18 / 42,43 \%)$. One patient with stage IIIB disease achieved sufficient tumour reduction to proceed to surgical resection with curative intent. Four of the 16 patients with stage IIIB disease subsequently received radical radiotherapy. Fourteen patients had stable disease and 10 patients had disease progression.

Survival. At the time of censor 28 of the 42 patients had died. The median follow-up for the 14 patients remaining alive was 13.5 (range 3.5-31.7) months. Survival data are shown in Fig. 3. Median survival for all patients was 12.5 months (95\% CI 6.7-16.5 months). One-year survival was $51 \%$ (95\% CI $\pm 16 \%)$.

\section{Discussion}

Gemcitabine in combination with carboplatin has been widely adopted as therapy for advanced NSCLC in the UK. This was 


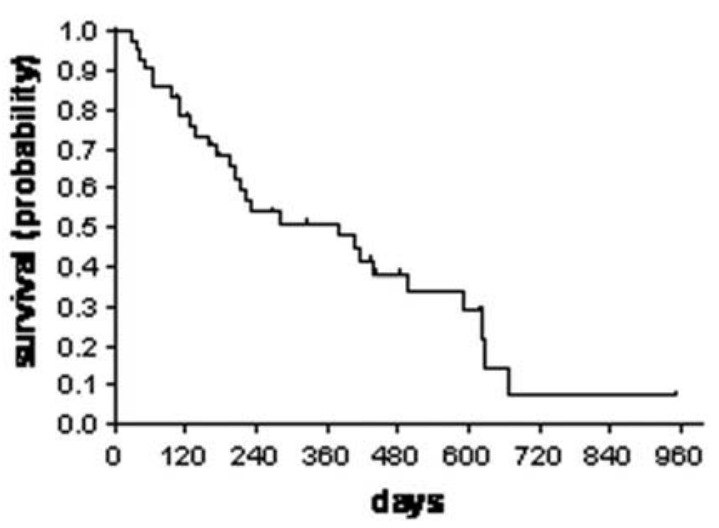

Figure 3. Kaplan-Meier survival curve. Total 42 patients; 28 deaths and 14 alive at time of censor (median follow-up 404 days). Median survival 377 days (95\% CI 200-495 days). One-year survival 51\% (95\% CI $\pm 16 \%$ ).

based upon superiority over older cisplatin-based regimens such as MIC (3). There is evidence that cisplatin in combination with newer drugs may be superior to the corresponding carboplatin-based combination $(4,6)$.

Cisplatin remains one of the important drugs in the treatment of lung cancer, though the question of its dosing and scheduling continues to be debated. The required cisplatin dose in a 3 -week cycle is $70-80 \mathrm{mg} / \mathrm{m}^{2}\left(23-27 \mathrm{mg} / \mathrm{m}^{2} /\right.$ week $)$. This dose requires prolonged hydration over an 8 -h schedule, presenting practical problems for most centres and many therefore administer cisplatin with pre-hydration in an inpatient setting when using doses in excess of $50-60 \mathrm{mg} / \mathrm{m}^{2}$. In the management of advanced NSCLC, where the primary goal is palliation of symptoms and the gain in survival is modest, using chemotherapy in an outpatient setting without compromising efficacy is a worthwhile aim. Splitting the cisplatin dose over weeks 1 and 2 and given concurrently with gemcitabine allows administration over a shorter time period in an outpatient setting. Importantly, this maintains the required cisplatin dose intensity. Furthermore, this schedule may facilitate the synergistic interaction between gemcitabine and cisplatin which may, in part, explain the encouraging survival reported in our study. Other studies have used spilt dose cisplatin over days 1,8 and 15 of a 28 -day schedule. Shepherd et al reported a phase II study using gemcitabine $1500 \mathrm{mg} / \mathrm{m}^{2}$ and cisplatin $30 \mathrm{mg} / \mathrm{m}^{2}$ on days 1,8 and 15 in a 28 day schedule with a response rate of $26 \%$ (12). Thirtyfour of the 40 patients had stage IV disease and the modest activity should be seen in light of these patient characteristics. Lippe et al reported a 36 patient phase II study using gemcitabine $1000 \mathrm{mg} / \mathrm{m}^{2}$ and cisplatin $35 \mathrm{mg} / \mathrm{m}^{2}$ on days 1,8 and 15 in a 28 -day schedule. Response rate was $33.3 \%$ and the median survival was 11.8 months. Median dose intensity for gemcitabine and cisplatin was 82 and $80 \%$, respectively, which is significantly lower than that achieved in our study (13). Berardi et al using the same 28 day schedule in elderly patients ( $\geq 70$ years) reported a response rate of $31.8 \%$ and median survival of 9 months (14). Many trials of these 28day regimens report frequent dose modifications and omissions particularly on day 15 in both lung and bladder cancer (13-15). Optimising delivered dose whilst minimizing dose delays and dose modifications due to toxicity may well have an impact on disease-free and overall survival (16). Phase III trials addressing this question in advanced NSCLC are required. The mean chemotherapy dose delivered in our trial was $780.1 \mathrm{mg} / \mathrm{m}^{2}$ for gemcitabine and $25.6 \mathrm{mg} / \mathrm{m}^{2}$ for cisplatin, with 26 out of 42 patients receiving the planned dose. We delivered 138 cycles of chemotherapy (276 doses), and encountered only 11 dose reductions (4\%), 5 dose delays by 1 week $(1.8 \%)$ and 6 dose omissions $(2.2 \%)$. The maintenance of dose intensity may well have contributed to encouraging response rates and survival results. In our study $62 \%$ of patients had distant metastatic disease, including 5 with brain metastases a known poor prognostic indicator. We included patients with GFR as low as $50 \mathrm{ml} / \mathrm{min}$. This study thus widens the spectrum of patients receiving cisplatin-based chemotherapy as many cisplatin containing trials exclude patients with GFR $<60 \mathrm{ml} / \mathrm{min}$. A response rate of $43 \%$, median survival of 12.5 months and 1-year survival rate of $51 \%$ in this group of patients is encouraging. Another recent phase II study using gemcitabine $1250 \mathrm{mg} / \mathrm{m}^{2}$ and cisplatin $35 \mathrm{mg} / \mathrm{m}^{2}$ on days 1 and 8 , in a 21 day cycle reported similar encouraging results with a response rate of $51 \%$ and median survival of 13.1 months (17). The findings presented here suggest this approach is a worthwhile and resource effective alternative to standard schedules, which maintains dose intensity and good treatment tolerance.

\section{Acknowledgements}

We gratefully acknowledge the support of Lilly UK, for the provision of study grant.

\section{References}

1. Cullen, MH, Billingham LJ, Woodroffe CM, et al: Mitomycin, ifosfamide and cisplatin in unresectable non-small-cell lung cancer: effects on survival and quality of life. J Clin Oncol 17: 3188-3194, 1999.

2. Non-Small Cell Lung Cancer Collaborative Group: Chemotherapy in non-small cell lung cancer: a meta-analysis using updated data on individual patients from 52 randomised clinical trials. Br Med J 311: 899-909, 1995.

3. Rudd RM, Gower NH, Spiro SG, et al: Gemcitabine plus carboplatin versus mitomycin, ifosfamide, and cisplatin in patients with stage IIIB or IV non-small-cell lung cancer: a phase III randomized study of the London Lung Cancer Group. J Clin Oncol 23: 142-153, 2005.

4. Fossella F, Pereiera JR, von Pawel J, et al: Randomized, multinational, phase III study of docetaxel plus platinum combinations versus vinorelbine plus cisplatin for advanced non-small-cell lung cancer: the TAX 326 Study Group. J Clin Oncol 21: 3016-3024, 2003.

5. Mazzanti P, Massacesi C, Rocchi MB, et al: Randomized, multicenter, phase II study of gemcitabine plus cisplatin versus gemcitabine plus carboplatin in patients with advanced nonsmall cell lung cancer. Lung Cancer 41: 81-89, 2003.

6. Rosell R, Gatzemeier U, Betticher DC, et al: Phase III randomised trial comparing paclitaxel/carboplatin with paclitaxel/cisplatin in patients with advanced non-small-cell lung cancer: a cooperative multinational trial. Ann Oncol 13: 1539-1549, 2002.

7. Klastersky J, Sculier JP, Lacroix H, et al: A randomized study comparing cisplatin or carboplatin with etoposide in patients with advanced non-small-cell lung cancer: European Organization for Research and Treatment of Cancer Protocol 07861. J Clin Oncol 8: 1556-1562, 1990.

8. Hotta K, Matsuo K, Ueoka H, et al: Meta-analysis of randomized clinical trials comparing cisplatin to carboplatin in patients with advanced non-small-cell lung cancer. J Clin Oncol 22: 3852-3859, 2004. 
9. Bergman AM, Ruiz van Haperen VW, Veerman G, et al: Synergistic interaction between cisplatin and gemcitabine in vitro. Clin Cancer Res 2: 521-530, 1996.

10. Crul M, van Waardenburg RC, Bocxe S, et al: DNA repair mechanisms involved in gemcitabine cytotoxicity and in the interaction between gemcitabine and cisplatin. Biochem Pharmacol 65: 275-282, 2003.

11. Kaplan EL and Meier P: Non-parametric estimation from incomplete observations. J Am Stat Assoc 53: 457-481, 1958.

12. Shepherd FA, Cormier Y, Burkes R, et al: Phase II trial of gemcitabine and weekly cisplatin for adavanced non-small cell lung cancer. Semin Oncol 24 (Suppl. 8): S27-S30, 1997.

13. Lippe P, Tummarello D, Monterubbianesi MC, et al: Weekly gemcitabine and cisplatin in advanced non-small cell lung cancer: a phase II study. Ann Oncol 10: 217-221, 1999.
14. Berardi R, Porfiri E, Scartozzi M, et al: Elderly patients with advanced non-small cell lung cancer: a phase II study with weekly cisplatin and gemcitabine. Oncology 65: 198-203, 2003.

15. Von der Maase H, Hansen SW, Roberts JT, et al: Gemcitabine and cisplatin versus methotrexate, vinblastine, doxorubicin and cisplatin in advanced or metastatic bladder cancer: results of a large, randomized, multinational, multicenter, phase III study. J Clin Oncol 18: 3068-3077, 2000

16. Hussain SA, Stocken DD, Riley P, et al: A phase I/II study of gemcitabine and fractionated cisplatin in an outpatient setting using a 21-day schedule in patients with advanced and metastatic bladder cancer. Br J Cancer 91: 844-849, 2004.

17. Kim JH, Lee DH, Shin HC, et al: A phase II study with gemcitabine and split dose cisplatin in patients with advanced non-small cell lung cancer. Lung Cancer 54: 57-62, 2006. 